\title{
Tips for learners of evidence-based medicine: 1. Relative risk reduction, absolute risk reduction and number needed to treat
}

\author{
Alexandra Barratt, Peter C. Wyer, Rose Hatala, Thomas McGinn, Antonio L. Dans, Sheri Keitz, \\ Virginia Moyer, Gordon Guyatt, for the Evidence-Based Medicine Teaching Tips Working Group
}

§ See related article page 347

$\mathrm{P}$

hysicians, patients and policy-makers are influenced not only by the results of studies but also by how authors present the results. ${ }^{1-4}$ Depending on which measures of effect authors choose, the impact of an intervention may appear very large or quite small, even though the underlying data are the same. In this article we present 3 measures of effect - relative risk reduction, absolute risk reduction and number needed to treat - in a fashion designed to help clinicians understand and use them. We have organized the article as a series of "tips" or exercises. This means that you, the reader, will have to do some work in the course of reading this article (we are assuming that most readers are practitioners, as opposed to researchers and educators).

The tips in this article are adapted from approaches developed by educators with experience in teaching evidencebased medicine skills to clinicians. ${ }^{5,6} \mathrm{~A}$ related article, intended for people who teach these concepts to clinicians, is available online at www.cmaj.ca/cgi/content/full/171/4/353/DC1.

\section{Clinician learners' objectives}

\section{Understanding risk and risk reduction}

- Learn how to determine control and treatment event rates in published studies.

- Learn how to determine relative and absolute risk reductions from published studies.

- Understand how relative and absolute risk reductions usually apply to different populations.

\section{Balancing benefits and adverse effects in individual patients}

- Learn how to use a known relative risk reduction to estimate the risk of an event for a patient undergoing treatment, given an estimate of that patient's risk of the event without treatment.

- Learn how to use absolute risk reductions to assess whether the benefits of therapy outweigh its harms.

\section{Calculating and using number needed to treat}

- Develop an understanding of the concept of number needed to treat (NNT) and how it is calculated.

- Learn how to interpret the NNT and develop an understanding of how the "threshold NNT" varies depending on the patient's values and preferences, the severity of possible outcomes and the adverse effects (harms) of therapy.

\section{Tip 1: Understanding risk and risk reduction}

You can calculate relative and absolute risk reductions using simple mathematical formulas (see Appendix 1). However, you might find it easier to understand the concepts through visual presentation. Fig. 1A presents data from a hypothetical trial of a new drug for acute myocardial infarction, showing the 30-day mortality rate in a group of patients at high risk for the adverse event (e.g., elderly patients with congestive heart failure and anterior wall infarction). On the basis of information in Fig. 1A, how would you describe the

\section{Teachers of evidence-based medicine:}

See the "Tips for teachers" version of this article online at www.cmaj.ca/cgi/content/full/171/4/353/DC1. It contains the exercises found in this article in fill-in-theblank format, commentaries from the authors on the challenges they encounter when teaching these concepts to clinician learners and links to useful online resources. 
effect of the new drug? (Hint: Consider the event rates in people not taking the new drug and those who are taking it.)

We can describe the difference in mortality (event) rates in both relative and absolute terms. In this case, these high-risk patients had a relative risk reduction of $25 \%$ and an absolute risk reduction of $10 \%$.

Now, let's consider Fig. 1B, which shows the results of a second hypothetical trial of the same new drug, but in a patient population with a lower risk for the outcome (e.g., younger patients with uncomplicated inferior wall myocardial infarction). Looking at Fig. 1B, how would you describe the effect of the new drug?

The relative risk reduction with the new drug remains at $25 \%$, but the event rate is lower in both groups, and hence the absolute risk reduction is only $2.5 \%$.

Although the relative risk reduction might be similar across different risk groups (a safe assumption in many if not most $\left.\operatorname{cases}^{7,8}\right)$, the absolute gains, represented by absolute risk reductions, are not. In sum, the absolute risk reduction becomes smaller when event rates are low, whereas the relative risk reduction, or "efficacy" of the treatment, often remains constant.

These phenomena may be factors in the design of drug trials. For example, a drug may be tested in severely affected people in whom the absolute risk reduction is likely to be impressive, but is subsequently marketed for use by less severely affected patients, in whom the absolute risk reduction will be substantially less.

The absolute risk reduction becomes smaller when event rates are low, whereas the relative risk reduction, or "efficacy" of the treatment, often remains constant

\section{The bottom line}

Relative risk reduction is often more impressive than absolute risk reduction. Furthermore, the lower the event rate in the control group, the larger the difference between relative risk reduction and absolute risk reduction.

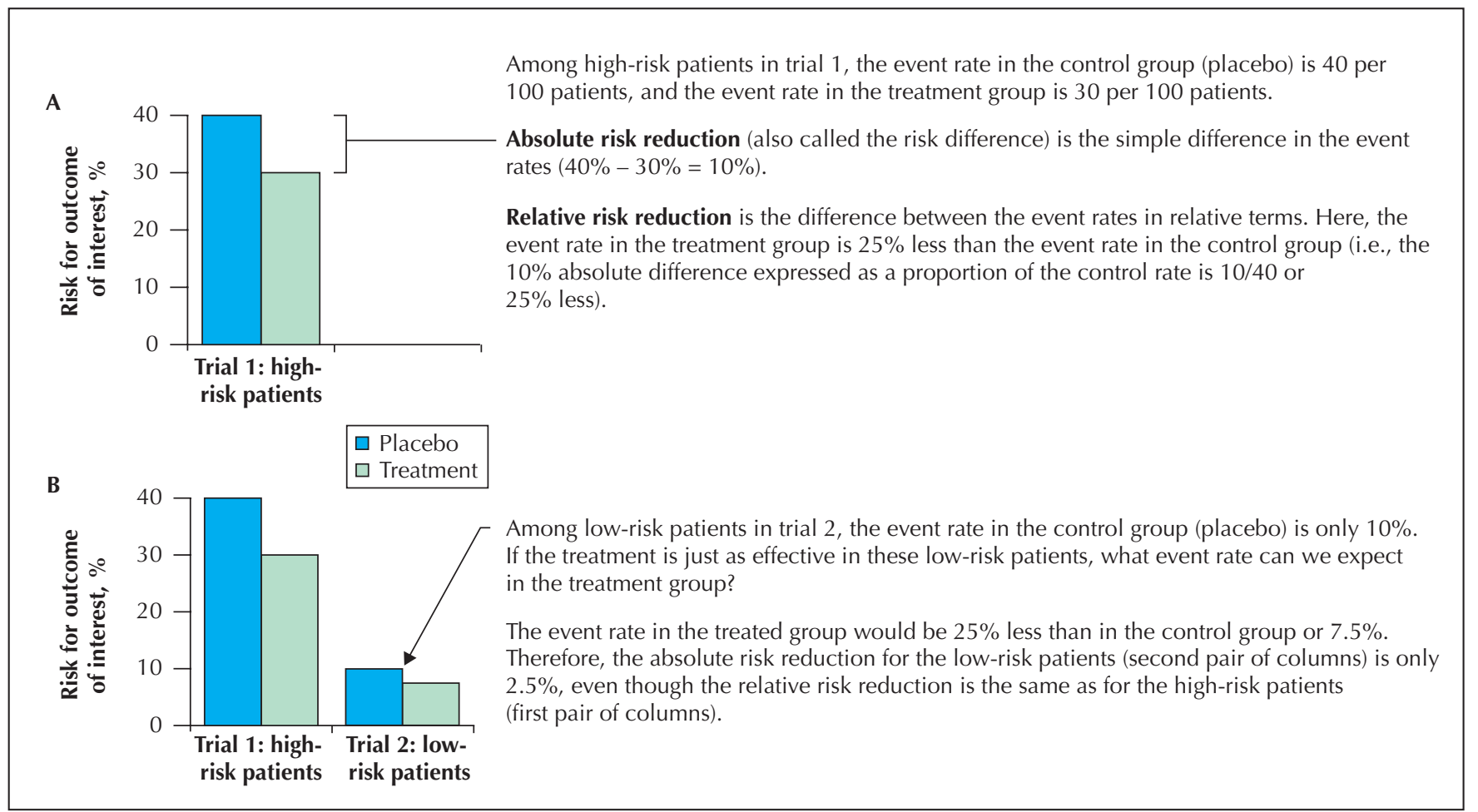

Fig. 1: Results of hypothetical placebo-controlled trials of a new drug for acute myocardial infarction. The bars represent the 30day mortality rate in different groups of patients with acute myocardial infarction and heart failure. A: Trial involving patients at high risk for the adverse outcome. B: Trials involving a group of patients at high risk for the adverse outcome and another group of patients at low risk for the adverse outcome. 


\section{Tip 2: Balancing benefits and adverse effects in individual patients}

In prescribing medications or other treatments, physicians consider both the potential benefits and the potential harms. We have just demonstrated that the benefits of treatment (presented as absolute risk reductions) will generally be greater in patients at higher risk of adverse outcomes than in patients at lower risk of adverse outcomes. You must now incorporate the possibility of harm into your decision-making.

First, you need to quantify the potential benefits. Assume you are managing 2 patients for high blood pressure and are considering the use of a new antihypertensive drug, drug $\mathrm{X}$, for which the relative risk reduction for stroke over 3 years is $33 \%$, according to published randomized controlled trials.

Pat is a 69-year-old woman whose blood pressure during a routine examination is $170 / 100 \mathrm{~mm} \mathrm{Hg}$; her blood pressure remains unchanged when you see her again 3 weeks later. She is otherwise well and has no history of cardiovascular or cerebrovascular disease. You assess her risk of stroke at about $1 \%$ (or 1 per 100 ) per year.'

Dorothy is also 69 years of age, and her blood pressure is the same as Pat's, $170 / 100 \mathrm{~mm} \mathrm{Hg}$; however, because she had a stroke recently, you assess her risk of subsequent stroke as higher than Pat's, perhaps $10 \%$ per year. ${ }^{10}$

One way of determining the potential benefit of a new treatment is to complete a benefit table such as Table 1A. To do this, insert your estimated 3-year event rates for Pat and Dorothy, and then apply the relative risk reduction (33\%) expected if they take drug X. It is clear from Table
1A that the absolute risk reduction for patients at higher risk (such as Dorothy) is much greater than for those at lower risk (such as Pat).

Now, you need to factor the potential harms (adverse effects associated with using the drug) into the clinical decision. In the clinical trials of drug $\mathrm{X}$, the risk of severe gastric bleeding increased 3 -fold over 3 years in patients who received the drug (relative risk of 3 ). A population-based study has reported the risk of severe gastric bleeding for women in your patients' age group at about $0.1 \%$ per year (regardless of their risk of stroke). These data can now be added to the table to allow a more balanced assessment of the benefits and harms that could arise from treatment (Table 1B).

Considering the results of this process, would you give drug $\mathrm{X}$ to Pat, to Dorothy or to both?

In making your decisions, remember that there is not necessarily one "right answer" here. Your analysis might go something like this:

Pat will experience a small benefit (absolute risk reduction over 3 years of about 1\%), but this will be considerably offset by the increased risk of gastric bleeding (absolute risk increase over 3 years of $0.6 \%$ ). The potential benefit for Dorothy (absolute risk reduction over 3 years of about $10 \%$ ) is much greater than the increased risk of harm (absolute risk increase over 3 years of $0.6 \%$ ). Therefore, the benefit of treatment is likely to be greater for Dorothy (who is at higher risk of stroke) than for Pat (who is at lower risk).

Assessment of the balance between benefits and harms depends on the value that patients place on reducing their risk of stoke in relation to the increased risk of gastric bleeding. Many patients might be much more concerned about the former than the latter.

\begin{tabular}{|c|c|c|c|}
\hline \multirow[b]{2}{*}{ Patient group } & \multicolumn{2}{|c|}{$3-y r$ event rate for stroke, $\%$} & \multirow{2}{*}{$\begin{array}{c}\text { Absolute } \\
\text { risk reduction, \% } \\
\text { (no treatment - treatment) }\end{array}$} \\
\hline & $\begin{array}{l}\text { No } \\
\text { treatment }\end{array}$ & $\begin{array}{l}\text { With treatment } \\
\quad(\text { drug } X)\end{array}$ & \\
\hline At lower risk (e.g., Pat) & 3 & 2 & 1 \\
\hline At higher risk (e.g., Dorothy) & 30 & 20 & 10 \\
\hline
\end{tabular}

Table 1B: Benefit and harm table

\begin{tabular}{|c|c|c|c|c|c|c|}
\hline \multirow[b]{2}{*}{ Patient group } & \multicolumn{3}{|c|}{3 -yr event rate for stroke, $\%$} & \multicolumn{3}{|c|}{ 3-yr event rate for severe gastric bleeding, \% } \\
\hline & $\begin{array}{c}\text { No } \\
\text { treatment }\end{array}$ & $\begin{array}{l}\text { With treatment } \\
\quad(\text { drug } X)\end{array}$ & $\begin{array}{l}\text { Absolute risk reduction } \\
\text { (no treatment - treatment) }\end{array}$ & $\begin{array}{c}\text { No } \\
\text { treatment }\end{array}$ & $\begin{array}{l}\text { With treatment } \\
\quad(\text { drug } X)\end{array}$ & $\begin{array}{c}\text { Absolute risk increase } \\
\text { (treatment - no treatment) }\end{array}$ \\
\hline $\begin{array}{l}\text { At lower risk } \\
\text { (e.g., Pat) }\end{array}$ & 3 & 2 & 1 & 0.3 & 0.9 & 0.6 \\
\hline $\begin{array}{l}\text { At higher risk } \\
\text { (e.g., Dorothy) }\end{array}$ & 30 & 20 & 10 & 0.3 & 0.9 & 0.6 \\
\hline
\end{tabular}

*Based on data from randomized controlled trials of drug X reporting a 33\% relative risk reduction for the outcome (stroke) over 3 years and a 3 -fold increase for the adverse effect (severe gastric bleeding) over the same period. 


\section{Number needed to treat: definitions}

Number needed to treat: the number of patients who would have to receive the treatment for 1 of them to benefit; calculated as 100 divided by the absolute risk reduction expressed as a percentage (or 1 divided by the absolute risk reduction expressed as a proportion; see Appendix 1)

Number needed to harm: the number of patients who would have to receive the treatment for 1 of them to experience an adverse effect; calculated as 100 divided by the absolute risk increase expressed as a percentage (or 1 divided by the absolute risk increase expressed as a proportion)

\section{The bottom line}

When available, trial data regarding relative risk reductions (or increases), combined with estimates of baseline (untreated) risk in individual patients, provide the basis for clinicians to balance the benefits and harms of therapy for their patients.

\section{Tip 3: Calculating and using number needed to treat}

Some physicians use another measure of risk and benefit, the number needed to treat (NNT), in considering the consequences of treating or not treating. The NNT is the number of patients to whom a clinician would need to administer a particular treatment to prevent 1 patient from having an adverse outcome over a predefined period of time. (It also reflects the likelihood that a particular patient to whom treatment is administered will benefit from it.) If, for example, the NNT for a treatment is 10 , the practitioner would have to give the treatment to 10 patients to prevent 1 patient from having the adverse outcome over the defined period, and each patient who received the treatment would have a 1 in 10 chance of being a beneficiary.

If the absolute risk reduction is large, you need to treat only a small number of patients to observe a benefit in at least some of them. Conversely, if the absolute risk reduction is small, you must treat many people to observe a benefit in just a few.

An analogous calculation to the one used to determine the NNT can be used to determine the number of patients who would have to be treated for 1 patient to experience an adverse event. This is the number needed to harm $(\mathrm{NNH})$, which is the inverse of the absolute risk increase.

How comfortable are you with estimating the NNT for a given treatment? For example, consider the following questions: How many 60-year-old patients with hypertension would you have to treat with diuretics for a period of 5 years to prevent 1 death? How many people with myocardial infarction would you have to treat with $\beta$ blockers for 2 years to prevent 1 death? How many people with acute myocardial infarction would you have to treat with streptokinase to prevent 1 person from dying in the next 5 weeks? Compare your answers with estimates derived from published studies (Table 2). How accurate were your estimates? Are you surprised by the size of the NNT values?

Physicians often experience problems in this type of exercise, usually because they are unfamiliar with the calculation of NNT. Here is one way to think about it. If a disease has a mortality rate of $100 \%$ without treatment and therapy reduces that mortality rate to $50 \%$, how many people would you need to treat to prevent 1 death? From the numbers given, you can probably figure out that treating 100 patients with the otherwise fatal disease results in 50 survivors. This is equivalent to 1 out of every 2 treated. Since all were destined to die, the NNT to prevent 1 death is 2 . The formula reflected in this calculation is as follows: the NNT to prevent 1 adverse outcome equals the inverse of the absolute risk reduction. Table 3 illustrates this concept further. Note that, if the absolute risk reduction is presented as a percentage, the NNT is

Table 2: Benefit table for patients with cardiovascular problems

\begin{tabular}{|c|c|c|c|c|}
\hline \multirow[b]{2}{*}{ Clinical question } & \multicolumn{2}{|c|}{ Event rate, \% } & \multirow[b]{2}{*}{ ARR, \% } & \multirow[b]{2}{*}{ NNT } \\
\hline & Control group & Treatment group & & \\
\hline $\begin{array}{l}\text { What is the reduction in risk of stroke within } 5 \\
\text { years among } 60 \text {-year-old patients with } \\
\text { hypertension who are treated with diuretics? } ?^{11}\end{array}$ & 2.9 & 1.9 & 1.00 & 100 \\
\hline $\begin{array}{l}\text { What is the reduction in risk of death within } 2 \\
\text { years after MI among } 60 \text {-year-old patients treated } \\
\text { with } \beta \text {-blockers? }\end{array}$ & 9.8 & 7.3 & 2.50 & 40 \\
\hline $\begin{array}{l}\text { What is the reduction in risk of death within } 5 \\
\text { weeks after acute } \mathrm{Ml} \text { among } 60 \text {-year-old patients } \\
\text { treated with streptokinase? }\end{array}$ & 12.0 & 9.2 & 2.80 & 36 \\
\hline
\end{tabular}

Note: $\mathrm{MI}=$ myocardial infarction, $\mathrm{ARR}=$ absolute risk reduction, $\mathrm{NNT}=$ number needed to treat . 
Table 3: Calculation of NNT from absolute risk reduction*

\begin{tabular}{lcc}
\hline $\begin{array}{l}\text { Form of absolute } \\
\text { risk reduction }\end{array}$ & $\begin{array}{c}\text { Calculation } \\
\text { of NNT }\end{array}$ & Example \\
\hline Percentage (e.g., 2.8\%) & 100/ARR & $100 / 2.8=36$ \\
Proportion (e.g., 0.028) & $1 /$ ARR & $1 / 0.028=36$ \\
\hline
\end{tabular}

*Using absolute risk reduction in last row of Table $2 .{ }^{13}$

100/absolute risk reduction; if the absolute risk reduction is expressed as a proportion, the NNT is 1/absolute risk reduction. Both methods give the same answer, so use whichever you find easier.

It can be challenging for clinicians to estimate the baseline risks for specific populations. For example, some physicians may have little idea of the risk of stroke over 5 years among patients with hypertension. Physicians may also overestimate the effect of treatment, which leads them to ascribe larger absolute risk reductions and smaller NNT values than are actually the case. ${ }^{14}$

Now that you know how to determine the NNT from the absolute risk reduction, you must also consider whether the NNT is reasonable. In other words, what is the maximum NNT that you and your patients will accept as justifying the benefits and harms of therapy? This is referred to as the threshold NNT. ${ }^{15}$ If the calculated NNT is above the threshold, the benefits are not large enough (or the risk of harm is too great) to warrant initiating the therapy.

Determinants of the threshold NNT include the patient's own values and preferences, the severity of the outcome that would be prevented, and the costs and side effects of the intervention. Thus, the threshold NNT will almost certainly be different for different patients, and there is no simple answer to the question of when an NNT is sufficiently low to justify initiating treatment.

\section{The bottom line}

NNT is a concise, clinically useful presentation of the effect of an intervention. You can easily calculate it from the absolute risk reduction (just remember to check whether the absolute risk reduction is presented as a percentage or a proportion and use a numerator of 100 or 1 accordingly). Be careful not to overestimate the effect of treatments (i.e., use a value of absolute risk reduction that is too high) and thus underestimate the NNT.

\section{Conclusions}

Clinicians seeking to apply clinical evidence to the care of individual patients need to understand and be able to calculate relative risk reduction, absolute risk reduction and NNT from data presented in clinical trials and systematic reviews. We have described and defined these concepts and presented tabular tools and equations to help clinicians overcome common pitfalls in acquiring these skills.
This article has been peer reviewed.

From the School of Public Health, University of Sydney, Sydney, Australia (Barratt); the Columbia University College of Physicians and Surgeons, New York, NY (Wyer); the Department of Medicine, University of British Columbia, Vancouver, BC (Hatala); Mount Sinai Medical Center, New York, NY (McGinn); the Department of Internal Medicine, University of the Philippines College of Medicine, Manila, The Philippines (Dans); Durham Veterans Affairs Medical Center and Duke University Medical Center, Durham, NC (Keitz); the Department of Pediatrics, University of Texas, Houston, Tex. (Moyer); and the Departments of Medicine and of Clinical Epidemiology and Biostatistics, McMaster University, Hamilton, Ont. (Guyatt)

Competing interests: None declared.

Contributors: Alexandra Barratt contributed tip 2, drafted the manuscript, coordinated input from coauthors and reviewers and from field-testing and revised all drafts. Peter Wyer edited drafts and provided guidance in developing the final format. Rose Hatala contributed tip 1, coordinated the internal review process and provided comments throughout development of the manuscript. Thomas McGinn contributed tip 3 and provided comments throughout development of the manuscript. Antonio Dans reviewed all drafts and provided comments throughout development of the manuscript. Sheri Keitz conducted field-testing of the tips and contributed material from the field-testing to the manuscript. Virginia Moyer reviewed and contributed to the final version of the manuscript. Gordon Guyatt helped to write the manuscript (as an editor and coauthor).

\section{References}

1. Malenka DJ, Baron JA, Johansen S, Wahrenberger JW, Ross JM. The framing effect of relative and absolute risk. 7 Gen Intern Med 1993;8:543-8.

2. Forrow L, Taylor WC, Arnold RM. Absolutely relative: How research results are summarized can affect treatment decisions. Am $\mathcal{F}$ Med 1992;92:121-4.

3. Naylor CD, Chen E, Strauss B. Measured enthusiasm: Does the method of reporting trial results alter perceptions of therapeutic effectiveness? Ann Intern Med 1992;117:916-21.

4. Fahey T, Griffiths S, Peters TJ. Evidence based purchasing: understanding results of clinical trials and systematic reviews. BMF 1995;311:1056-60.

5. Jaeschke R, Guyatt G, Barratt A, Walter S, Cook D, McAlister F, et al. Measures of association. In: Guyatt G, Rennie D, editors. The users' guides to the medical literature: a manual of evidence-based clinical practice. Chicago: AMA Publications; 2002. p. 351-68.

6. Wyer PC, Keitz S, Hatala R, Hayward R, Barratt A, Montori V, et al. Tips for learning and teaching evidence-based medicine: introduction to the series. CMA7 2004:171(4):347-8.

7. Schmid CH, Lau J, McIntosh MW, Cappelleri JC. An empirical study of the effect of the control rate as a predictor of treatment efficacy in meta-analysis of clinical trials. Stat Med 1998;17:1923-42.

8. Furukawa TA, Guyatt GH, Griffith LE. Can we individualise the number needed to treat? An empirical study of summary effect measures in metaanalyses. Int 7 Epidemiol 2002;31:72-6.

9. SHEP Cooperative Research Group. Prevention of stroke by anti-hypertensive drug treatment in older persons with isolated systolic hypertension. Final results of the Systolic Hypertension in the Elderly Program (SHEP). FAMA 1991;265:3255-64.

10. SALT Collaborative Group. Swedish Aspirin Low-dose Trial (SALT) of $75 \mathrm{mg}$ aspirin as secondary prophylaxis after cerebrovascular events. Lancet 1991;338:1345-9.

11. Psaty BM, Smith NL, Siscovick DS, Koepsell TD, Weiss NS, Heckbert SR. Health outcomes associated with antihypertensive therapies used as first-line agents. A systematic review and meta-analysis. $7 A M A$ 1997;277: 739-45.

12. $\beta$-Blocker Health Attack Trial Research Group. A randomized trial of propranolol in patients with acute myocardial infarction. I. Mortality results. FAMA 1982;247:1707-14.

13. ISIS-2 Collaborative Group. Randomised trial of intravenous streptokinase, oral aspirin, both or neither among 17187 cases of suspected acute myocardial infarction: ISIS-2. Lancet 1988;2:349-60.

14. Chatellier G, Zapletal E, Lemaitre D, Menard J, Degoulet P. The number needed to treat: a clinically useful nomogram in its proper context. $B M 71996$; 312:426-9

15. Sinclair JC, Cook RJ, Guyatt GH, Pauker SG, Cook DJ. When should an effective treatment be used? Derivation of the threshold number needed to treat and the minimum event rate for treatment. 7 Clin Epidemiol 2001;54:253-62.

Correspondence to: Dr. Peter C. Wyer, 446 Pelhamdale Ave., Pelham NY 10803, USA; fax 212 305-6792; pwyer@worldnet .att.net 


\section{Members of the Evidence-Based Medicine Teaching Tips}

Working Group: Peter C. Wyer (project director), Columbia University College of Physicians and Surgeons, New York, NY; Deborah Cook, Gordon Guyatt (general editor), Ted Haines, Roman Jaeschke, McMaster University, Hamilton, Ont.; Rose Hatala (internal review coordinator), Department of Medicine, University of British Columbia, Vancouver, BC; Robert Hayward (editor, online version), Bruce Fisher, University of Alberta, Edmonton, Alta.; Sheri Keitz (field-test coordinator), Durham Veterans Affairs Medical Center and Duke University, Durham, NC; Alexandra Barratt, University of Sydney, Sydney, Australia; Pamela Charney, Albert Einstein College of Medicine, Bronx, NY; Antonio L. Dans, University of the Philippines College of Medicine, Manila, The Philippines; Barnet Eskin, Morristown Memorial Hospital, Morristown, NJ; Jennifer Kleinbart, Emory University, Atlanta, Ga.; Hui Lee, formerly Group Health Centre, Sault Ste. Marie, Ont. (deceased); Rosanne Leipzig, Thomas McGinn, Mount Sinai Medical Center, New York, NY; Victor M. Montori, Department of Medicine, Mayo Clinic College of Medicine, Rochester, Minn.; Virginia Moyer, University of Texas, Houston, Tex.; Thomas B. Newman, University of California, San
Francisco, Calif.; Jim Nishikawa, University of Ottawa, Ottawa, Ont.; W. Scott Richardson, Wright State University, Dayton, Ohio; Mark C. Wilson, University of lowa, lowa City, lowa

$\begin{aligned} & \text { Appendix 1: Formulas for commonly used measures of } \\
& \text { therapeutic effect }\end{aligned}$
\begin{tabular}{ll} 
Measure of effect & \multicolumn{1}{c}{ Formula } \\
\hline Relative risk & $\begin{array}{l}\text { (Event rate in intervention group) } \div \text { (event } \\
\text { rate in control group) }\end{array}$ \\
Relative risk reduction & $\begin{array}{l}1-\text { relative risk } \\
\text { or } \\
\text { (Absolute risk reduction) } \div \text { (event rate in } \\
\text { control group) } \\
\text { (Event rate in intervention group) }- \text { (event } \\
\text { rate in control group) } \\
\text { Absolute risk reduction }\end{array}$ \\
Number needed to treat & $1 \div$ (absolute risk reduction) \\
\hline
\end{tabular}

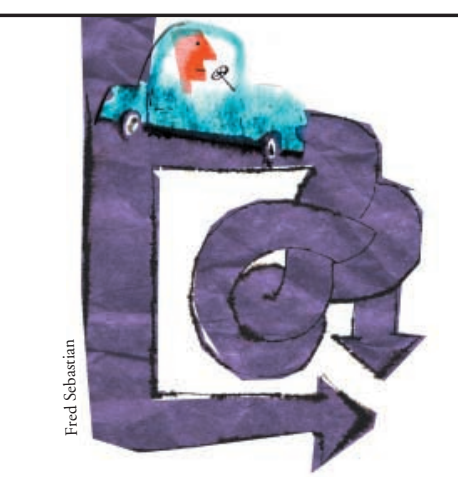

\section{Please, reader, can you spare some time?}

Our annual CMAJ readership survey begins September 20. By telling us a little about who you are and what you think of $C M A J$, you'll help us pave our way to an even better journal. For 2 weeks, we'll be asking you to take the survey route on one of your visits to the journal online. We hope you'll go along with the detour and help us stay on track.

\section{Chers lecteurs et lectrices, pourriez-vous nous accorder un moment?}

Le sondage annuel auprès des lecteurs du JAMC débute le 20 septembre. En nous parlant un peu de vous et de ce que vous pensez du JAMC, vous nous aiderez à améliorer encore le journal. Pendant deux semaines, lorsque vous rendrez visite au journal électronique, nous vous demanderons de passer une fois par la page du sondage. Nous espérons que vous accepterez de faire ce détour qui contribuera à nous garder sur la bonne voie. 